\title{
Article
}

\section{A system to investigate the remediation of organic vapors using microwave- induced plasma with fluidized carbon granules}

Dawson, Elizabeth A., Parkes, Gareth M. B., Bond, Gary and Mao, Runjie

Available at https://clok.uclan.ac.uk/5380/

Dawson, Elizabeth A., Parkes, Gareth M. B., Bond, Gary orcid iconORCID: 0000-0001-5347-2341 and Mao, Runjie (2009) A system to investigate the remediation of organic vapors using microwave-induced plasma with fluidized carbon granules. Review of Scientific Instruments, 80 (3). 034102. ISSN 00346748

It is advisable to refer to the publisher's version if you intend to cite from the work. http://dx.doi.org/10.1063/1.3089823

For more information about UCLan's research in this area go to http://www.uclan.ac.uk/researchgroups/ and search for <name of research Group>.

For information about Research generally at UCLan please go to http://www.uclan.ac.uk/research/

All outputs in CLoK are protected by Intellectual Property Rights law, including Copyright law. Copyright, IPR and Moral Rights for the works on this site are retained by the individual authors and/or other copyright owners. Terms and conditions for use of this material are defined in the policies page. 


\title{
Infrared and microwaves at $5.8 \mathrm{GHz}$ in a catalytic reactor
}

\author{
Etienne Séguin, Sébastien Thomas, Philippe Bazin, Gary Bond, $\dagger$ Carlos Henriques $\ddagger$ \\ and Frédéric Thibault-Starzyk*
}

Received 16th October 2008, Accepted 18th December 2008

First published as an Advance Article on the web 29th January 2009

DOI: $10.1039 / \mathbf{b 8 1 8 2 6 0 d}$

An improved micro-reactor cell for IR spectroscopic studies of heterogeneous catalysis was built around a $5.8 \mathrm{GHz}$ microwave cavity. The reactor can operate at 20 bars and with conventional heating up to $720 \mathrm{~K}$, with reactant gas flows velocities (GHSV) from 25000 to $50000 \mathrm{~h}^{-1}$. The temperature of the sample under microwave irradiation was measured by time resolved IR emission spectroscopy. The first experiment performed was the IR monitoring of the desorption of carbonates induced by irradiating an alumina sample by microwaves at $5.8 \mathrm{GHz}$.

\section{Introduction}

Infrared operando spectroscopy is the infrared study of the chemistry inside a functioning reactor, under real working conditions. It is a powerful technique for the identification of surface intermediates in heterogeneous catalysis. $^{1-5}$ Such studies aim to establish correlations between catalytic data (activity and selectivities) and perturbation of the catalytic surface (temperature and surface concentration of different species) while simultaneously interrogating adsorbed species at the catalyst surface. ${ }^{6}$ These types of experiments enable determination of the selective active sites and eventually an understanding of heterogeneous reaction mechanisms. $^{7}$

Traditional steady-state techniques have been successfully applied for kinetic studies, but they often lack molecular detail due to low time resolution, leading to macrokinetic models providing a global description of the reaction system. ${ }^{8,9}$ Transient methods and dynamic testing allows the reaction to be analyzed as individual steps, giving more insight into the functioning of the catalyst. Transient behaviour is obtained by analysing the system response to a perturbation of one or more state variables: pressure, temperature, composition and flow rate. ${ }^{10-12}$ When using infrared spectroscopy as a response analyser system, intermediate species and reaction pathways can be detected depending on their lifetimes: ${ }^{13-15}$ only those species having lifetimes greater than the time required for acquisition of the spectra can be detected. Time-resolution can reach 50-100 scans per second with "rapid-scan" FTIR instruments. Operando IR reactor-cells have been developed with high pressure (20 bars) and high temperature $(800 \mathrm{~K})$ capabilities, with very low dead volume for high time resolution. ${ }^{16}$

Microwave heating has been well known since the Eighties with the development of domestic microwave ovens, and has attracted

Laboratoire Catalyse et Spectrochimie, ENSICAEN, Université de

Caen, CNRS, 6 Bd Maréchal Juin, F-14050 Caen, France.

E-mail:fts@ensicaen.fr

$\dagger$ Permanent address: Centre for Materials Science, University of Central Lancashire, Preston, UK PR1 2HE.

$\ddagger$ Permanent address: IBB/CEBQ, Instituto Superior Técnico, Av. Rovisco Pais, 1049-001 Lisboa, Portugal. much interest in analytical and synthetic chemistry and more recently in heterogeneous catalysis. ${ }^{17,18}$ Studies of heterogeneous catalysts under conditions of microwave stimulation have shown that microwaves are capable of producing a rapid increase of reaction temperature and can modify selectivity. ${ }^{19-29}$ The impact of microwaves on the reaction can be due to a thermal effect ${ }^{20,23,26}$ or to an influence on the electronic structure of the reactants, ${ }^{27-29}$ but this is still a matter of debate. ${ }^{30,31}$ A new tool for studying surface chemistry under microwave irradiation can help understanding.

Specific infrared cells have been designed recently for studying catalytic reactions under microwaves. ${ }^{17,18}$ Heating rates in excess of $100 \mathrm{~K} \mathrm{~min}^{-1}$ can be achieved by using microwave heating (without spectroscopic observation). ${ }^{20,26,32,33,34}$ During such rapid heating and depending on the kinetics of the studied reaction, the catalyst-adsorbed molecules-gas phase system can be put out of equilibrium. As a consequence, reaction intermediates which are sometimes difficult to detect and characterize under steady state conditions, can be present in larger amounts. Consequently, a microwave reactor with operando spectroscopy features can have several interesting aspects: it can be used to introduce a rapid perturbation of the reaction conditions by a temperature pulse and it can open new vistas on the influence of microwave on reaction mechanisms and selectivities.

In the present paper, a new microwave-heated operando IR cell is presented, allowing the study of the dynamic behaviour of catalytic systems. The microwave frequency is $5.8 \mathrm{GHz}$, which leads to better absorption of microwaves by the catalyst. The new IR catalytic reactor-cell can operate at high pressure (up to 20 bar), it has conventional heating up to $720 \mathrm{~K}$ that can be combined with the microwave irradiation and has a very low dead volume for high time resolution on the surface and in on-line gas analysis. IR emission spectroscopy is used to estimate the sample temperature, while transmission IR spectroscopy is used for the characterisation of surface species. Validation of this new tool was performed in a study of water desorption and carbonate decomposition on the surface of pure alumina, comparing microwave and conventional heating. 


\section{Experimental}

\section{Reactor cell}

The design of a microwave-heated operando IR reactor has several constraints. The use of microwave heating limits the range of materials that can be used in its construction. Due consideration must be given as to whether the material must transmit, reflect or be transparent to the microwave radiation. The cell must be designed with a clear optical path so as to let the infrared beam through the cell with minimal loss of intensity. It must also have as small a dead volume as possible in order to maximize the time resolution for comparing surface concentrations with on-line gas analysis. Fig. 1 shows a $3 \mathrm{D}$ view of the new microwave heated reactor/transmission infra-red cell.

The cell is adapted from an operando cell developed by Saussey et $a l .{ }^{16}$ which has proved its reliability over many years of operando studies. ${ }^{1}$ The catalyst is pressed as a self supporting wafer and placed in a glass ceramic $\left(\right.$ Macor $^{\circledR}$ ) sample holder (Fig. 2). The sample holder itself is located between two metallic plates (brass) with machined grids in the centre to let the IR beam through. The brass plates form the basis of a parallel plate applicator which is used to heat the catalyst disc. One of the plates is connected to the microwave generator at one end and to a water load at the other end and forms the positive plate of the applicator; the other plate forms the ground plate. Connections to the generator and water load are made by means of two coaxial cables fitted with $\mathrm{N}$-type connectors (Fig. 3) which were modified at one end so as to connect to the applicator plate via a copper wire. The cell can be attached to a stand with electrical insulation between the cell and the spectrometer.

A thermocoax ${ }^{\circledR}$ heating element is placed near the sample holder for conventional heating, regulated by a K-type thermocouple, placed outside the microwave field.

The minimisation of the dead-volume (sample cavity has about $0.2 \mathrm{~cm}^{3}$ ) as well as cell sealing is obtained by $\mathrm{KBr}$ windows, nuts and Kalrez ${ }^{\mathrm{R}} \mathrm{O}$-rings, all placed out of the microwave field, compressed by air-cooled brass flanges screwed (hand-tight) on each side of the reactor cell. The

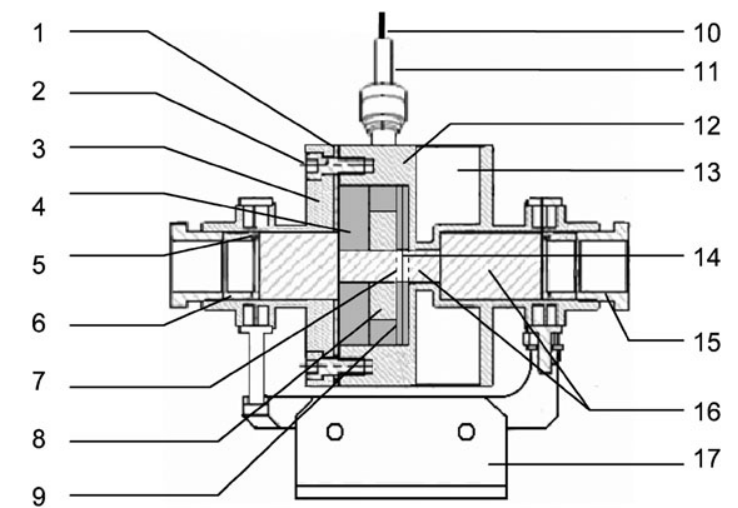

Fig. 2 Microwave reactor-IR cell (longitudinal cut). 1-TGBS gasket; 2 - cell closing screw; 3 - stainless steel lid; 4 - Macor $^{\circledR}$ filler; 5 - o-ring; 6 - stainless steel nut; 7,8 - microwave active brass grid and body of applicator; 9- Macor $^{\circledR}$ sample holder; 10 - copper wire; $11-1 / 4^{\prime \prime}$ pipe; 12-brass body; 13-heating element; 14 -sample; 15-brass nut; $16 \mathrm{KBr}$ and $\mathrm{CaF}_{2}$ windows; 17 - cell stand.

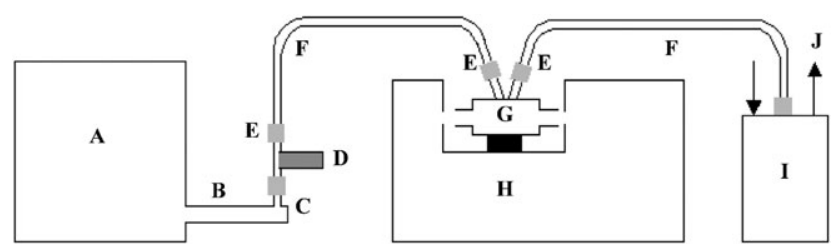

Fig. 3 Experimental setup: A - microwave generator; B - waveguide; $\mathrm{C}$-waveguide-coaxial transition; D — coaxial sliding short; E-coaxial cable connections; F-coaxial cables; G-reactor-cell; H-FTIR spectrometer; I-water load; J—water cooling circulation.

sample wafer is $\sim 20 \mathrm{mg}$, with a diameter of $16 \mathrm{~mm}$. Standard reaction conditions correspond to $W / F \sim 0.05 \mathrm{~g} \mathrm{~s}^{-1} \mathrm{~cm}^{-3}$. The IR cell reactor is fitted to a gas flow system, where GHSV values of 25000 to $50000 \mathrm{~h}^{-1}$ can be obtained. The flow pattern of this cell corresponds to a laminar flow $\left(5<N_{\operatorname{Re}}<15\right)$, similar to what can be found in monolithshaped catalysts where the reactants contact both sides of the catalyst. $^{33}$

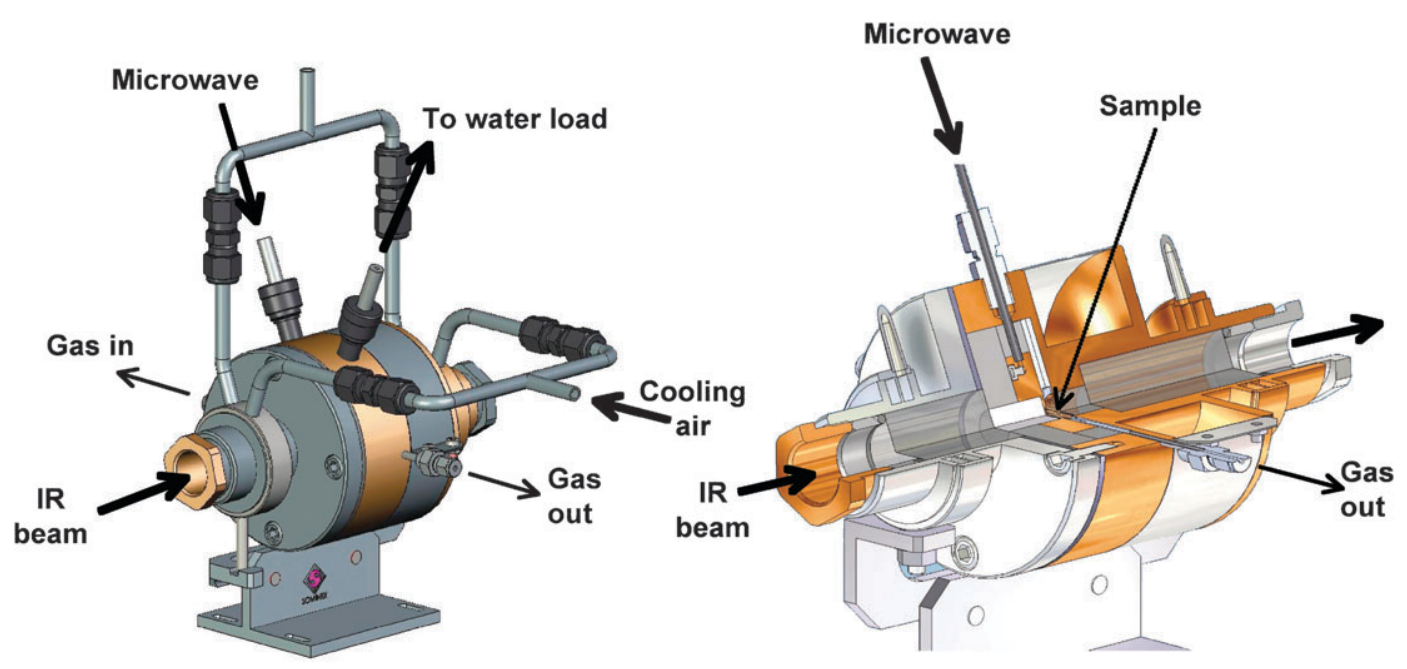

Fig. 1 General view of the microwave reactor-IR cell. 


\section{Microwave generator}

The microwave source is a variable power $(150-1000 \mathrm{~W})$ 5.8-GHz generator provided by Covimag (Brive-la-Gaillarde, France). Input and reflected powers can be directly read on a digital display and dissipated powers can easily be calculated. The use of a microwave frequency of $5.8 \mathrm{GHz}$ in these experiments should improve the transfer of energy into heat at least by a factor of two over the more conventionally used $2.45 \mathrm{GHz}$ due to the dependence of dielectric loss on frequency. Microwave adsorption by the small self supported wafer is also improved with the shorter wavelength $(5.13 \mathrm{~cm}$ for $5.8 \mathrm{GHz}$ ). Moreover, the shorter the wavelength, the smaller the cavity and this allows the very small dead-volume which is critical for high time-resolution via gas analysis. A coaxial sliding short is placed after the waveguide/coaxial transition accessory located at the extremity of the generator, in order to optimise the power transfer to the sample, as well as to minimize reflected energy (Fig. 3).

\section{IR monitoring of the microwave irradiation}

Infra-red measurements were performed with an MCT detector on a Bruker IFS 66/S FTIR spectrometer with an optical resolution of $4 \mathrm{~cm}^{-1}$. Two types of configurations were used: transmission for monitoring surface species during the experiment, and emission spectroscopy for estimating the sample temperature under microwave irradiation.

The average temperature of the wafer was determined by time-resolved IR emission spectroscopy. In emission configuration (Fig. 4), the hot sample plays the role of the infra-red source. A temperature vs. interferogram intensity calibration was done by measuring the interferogram intensity in the $4000-1000 \mathrm{~cm}^{-1}$ range for IR light emitted by the sample under conventional heating in a flow of argon $\left(\mathrm{GHSV}=40000 \mathrm{~h}^{-1}\right)$. The calibration was then used to estimate the temperature of the sample under microwave.

The sample was a $20 \mathrm{mg}$ (16 mm diameter) self supported wafer of $\gamma-\mathrm{Al}_{2} \mathrm{O}_{3}\left(194 \mathrm{~m}^{2} \mathrm{~g}^{-1}\right)$.

Water desorption and carbonate decomposition experiments under both microwave and conventional heating (transmission configuration, Fig. 4) were performed with no pre-adsorption, since alumina already contains water and carbonates on its surface after exposure to an ambient atmosphere. These tests were performed starting from $304 \mathrm{~K}$ under a flow of argon $\left(\mathrm{GHSV}=40000 \mathrm{~h}^{-1}\right)$.

In the conventional heating experiment, the sample was first kept at room temperature for two hours, and then heated to

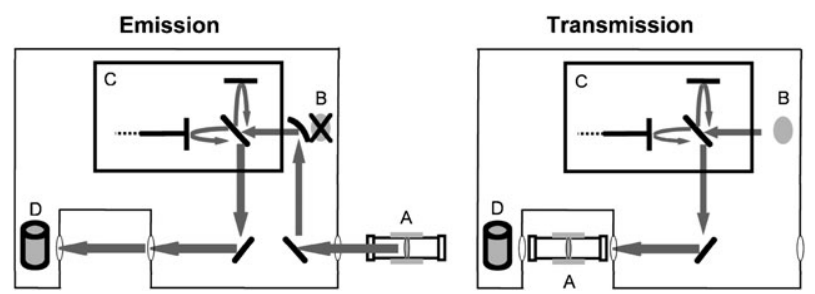

Fig. 4 FTIR experiment configuration in emission (left) and in transmission mode (right): A - microwave reactor cell; B - IR source; C-Michelson interferometer; D-MCT detector.
$440 \mathrm{~K}$ at a rate of $0.7 \mathrm{~K} \mathrm{~min}^{-1}$, the sample was then held at the final temperature for one hour.

In the microwave heating experiment, the sample was irradiated during $1 \mathrm{~min}$ by $275 \mathrm{~W}$ microwaves $(300 \mathrm{~W}$ emitted by the generator, $25 \mathrm{~W}$ reflected). Most of the energy was absorbed by the water load, and estimating the amount of energy actually absorbed by the sample is not possible for the moment. Data were recorded during a total of $5 \mathrm{~min}$ : $1 \mathrm{~min}$ before, and $3 \mathrm{~min}$ after irradiation. The experiment was performed in both the emission configuration (for measuring the sample temperature) and in the transmission configuration (to measure the infrared spectrum of the surface).

\section{Results and discussion}

\section{Measurement of the temperature by emission spectroscopy}

One of the major problems with the design of a microwave reactor for operando studies is the measurement of the temperature at catalyst surface. A thermocouple cannot be introduced into the microwave field without strongly perturbing it, which is highly undesirable. Fibre optic temperature sensors can only be used up to $500 \mathrm{~K}$ due to optical fibre material limitations. In order to overcome these problems we propose the use of infrared emission spectroscopy to obtain a fast time-resolved measurement of temperature, by using the black body radiation of the sample during microwave heating.

Fig. 5 shows the interferogram intensity as a function of sample temperature (obtained with conventional heating). Experimental points are fitted to a power-type trend line according to the Stefan-Boltzmann black body law: ${ }^{35}$

$$
M=\sigma T^{4}
$$

where $M$ is the power emitted per square meter by a black body. This value is proportional to the emission interferogram intensity $(I) . T$ is the average temperature of the wafer in Kelvin and $\sigma$ is the Stefan constant $\left(5.67 \times 10^{-8} \mathrm{~W} \mathrm{~m}^{-2} \mathrm{~K}^{-4}\right)$. The fitted values give rise to the following calibration function:

$$
T=\left(\frac{I}{1.87 \times 10^{-7}}\right)^{0.254}
$$

This method allows estimation of the average temperature of the catalyst pellet in the microwave field during catalytic experiments. As stated before, the sample temperature cannot

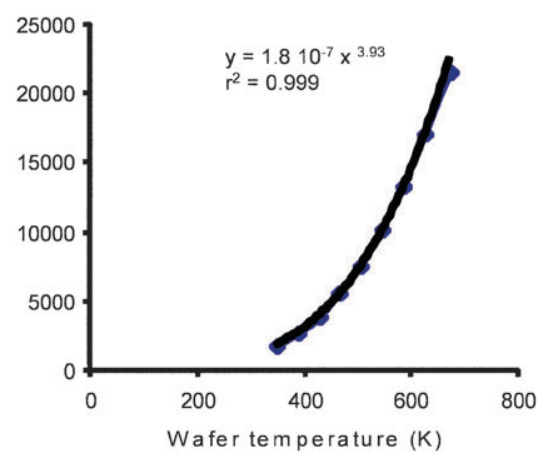

Fig. 5 Stefan-Boltzmann dependence of interferogram intensity. 

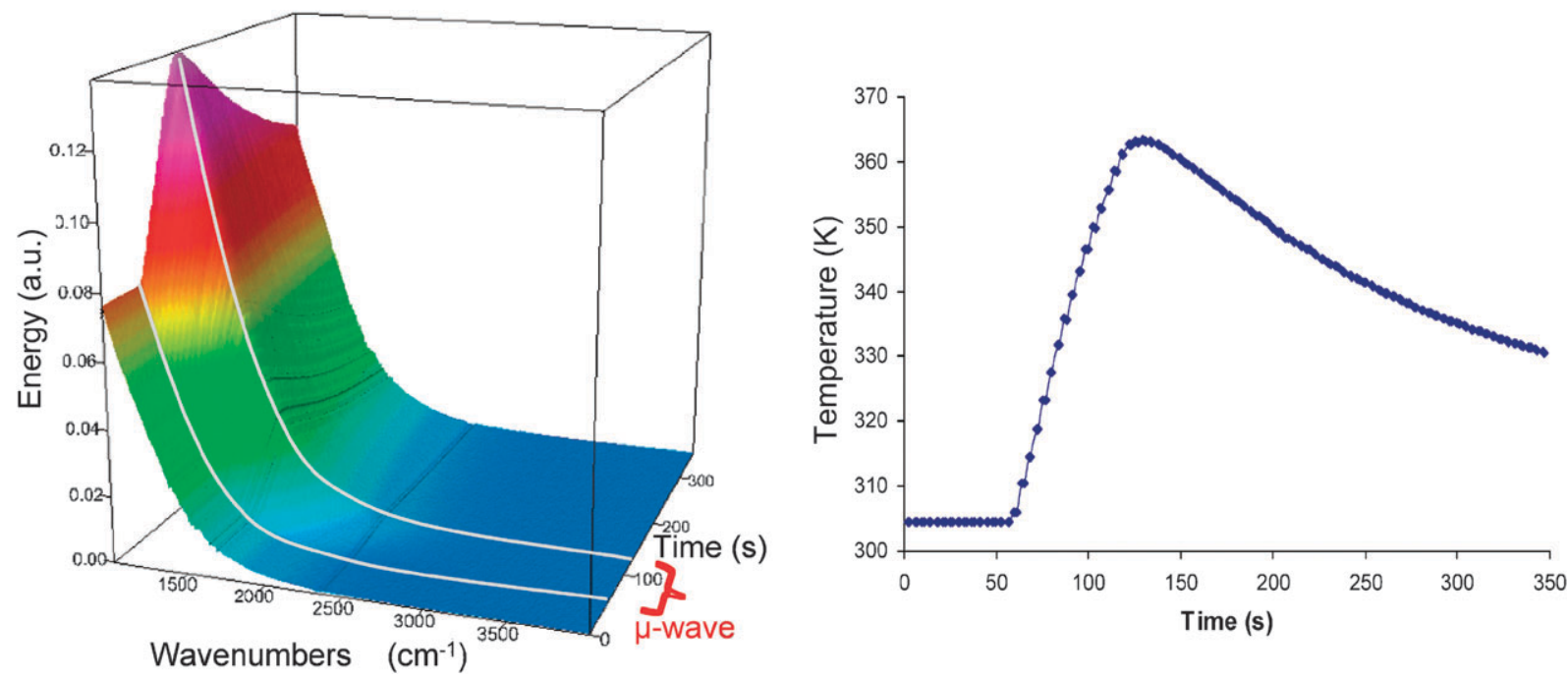

Fig. 6 Left: emission spectra of alumina during microwave irradiation. Right: temperature obtained by the black body law.

be measured with a thermocouple as no metallic part can be put in the cavity during microwave irradiation.

The temperature-increase measured by the optical fibre placed near the wafer (in contact with the Macor ${ }^{\circledR}$ sample holder) is only $20 \mathrm{~K}$. This corresponds to the temperature increase of the sample holder itself. This was expected with microwave heating, since Macor ${ }^{\circledR}$ does not absorb microwave and is only heated by conduction. This setup was applied during microwave irradiation of a pellet of $20 \mathrm{mg}$ alumina. Fig. 6, left, shows emission spectra recorded during the experiment. By using the Stefan-Boltzmann dependence of interferogram intensity on the temperature, it is possible to plot the temperature as a function of time (Fig. 6, right).

The temperature increase appears clearly as soon as microwaves are turned on (at $t=60 \mathrm{~s}$ ). After $60 \mathrm{~s}$ of microwave heating, the temperature reaches $365 \mathrm{~K}$ which corresponds to a $60 \mathrm{~K}$ temperature rise. The temperature starts to decrease immediately after the microwaves are switched off. The evolution of the average temperature depends on the nature of the sample. Using samples with different dielectric properties, we found different heating rates, which confirm that the sample is mostly heated by the microwaves and not by the metal parts surrounding it. A temperature rise of $60 \mathrm{~K}$ in one minute might seem like a moderate heating, but pure alumina does not absorb microwave significantly (very low dielectric loss: $\left.\tan \delta<10^{-4}\right)^{36}$ compared to other materials like $\mathrm{SiC}$ (results not shown), and the present results demonstrate the potential of microwave at $5.8 \mathrm{GHz}$ for catalytic studies. Adsorbed species like water and carbonates might contribute to the heating. Any metal introduced in the catalyst would considerably increase the dielectric loss and thus the heating by microwaves.

\section{Carbonate decomposition}

The rapid temperature increase generated by microwaves can result in the initiation of a surface reaction or, in a more simplistic way, give rise to a desorption/decomposition process. In this study a relatively simple process has been studied: water desorption and carbonates decomposition on alumina. Initially, the process was studied using conventional heating at a very low temperature rate $\left(0.7 \mathrm{~K} \mathrm{~min}^{-1}\right)$, corresponding to processes near equilibrium. The integrated area of water $\left(1635 \mathrm{~cm}^{-1}\right)$ and carbonates bands $\left(1410 \mathrm{~cm}^{-1}\right.$ and $1520 \mathrm{~cm}^{-1}$ ) and the temperature are plotted as a function of time in Fig. 7. The complete desorption of both water and carbonates is achieved at $\sim 440 \mathrm{~K}$.

The same experiment was performed with microwave heating starting from $304 \mathrm{~K}$. In this case, a much-higher temperature rate (roughly, two orders of magnitude higher) was obtained, about $1 \mathrm{~K} \mathrm{~s}^{-1}$. Fig. 7 (right) shows the evolution of infra-red bands obtained in the range $1250-1800 \mathrm{~cm}^{-1}$. Bands corresponding to water and carbonates on alumina start decreasing immediately with microwave irradiation $(t=60 \mathrm{~s})$. However, after $60 \mathrm{~s}$ of microwave irradiation, carbonates and water are still largely present on the surface of alumina which does not correspond to total decomposition.

The desorption and decomposition processes continue even after the microwaves have stopped $(t=120 \mathrm{~s})$, whereas temperature is already decreasing. Moreover, the $60 \mathrm{~K}$ temperature increase, measured by IR emission, should correspond to a desorption of approximately half the carbonates and water from the surface if the system was at equilibrium (as observed in the experiment performed under conventional heating). On the contrary, in the microwave heating experiment, only $10 \%$ of carbonates are decomposed and $20 \%$ of water is desorbed. This reveals the dynamics of desorption in the infrared cell, showing that transient-state phenomena can be easily achieved. In this particular case, this is not directly linked to the average temperature measured by emission spectroscopy. Desorption from hot zones in the sample (out of the IR beam) and re-adsorption in colder parts under the IR beam can justify the concentration increase observed before desorption. Microwaves are known to lead to hot spots on powder solids. On supported alumina catalysts, the spot size has been measured to be $90 \mu \mathrm{m}$, and $100-200 \mathrm{~K}$ hotter than the average surrounding alumina ${ }^{23}$. The temperature is homogenised by conduction in the sample after the microwaves stop.

This new device is now being applied to the study of the $\mathrm{CH}_{4}$-selective catalytic reduction of $\mathrm{NO}_{x}$, over metal-exchanged 

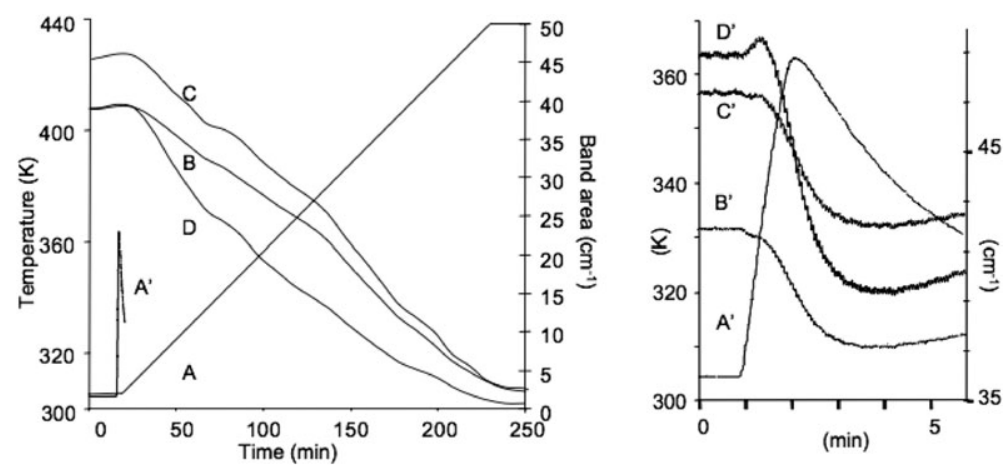

Fig. 7 Temperature and integrated intensities of water and carbonates bands during conventional (left) and microwave heating (right): A, A'-temperature; $\mathrm{B}, \mathrm{B}^{\prime}$ - carbonate band at $1410 \mathrm{~cm}^{-1} ; \mathrm{C}, \mathrm{C}^{\prime}$ - water band at $1635 \mathrm{~cm}^{-1} ; \mathrm{D}, \mathrm{D}^{\prime}$-carbonate band at $1515 \mathrm{~cm}^{-1}$. The temperature increase $\left(\mathrm{A}^{\prime}\right)$ during the microwave experiment is added in the data for the conventional heating for the sake of comparison.

zeolite catalysts, with the aim of detecting reaction intermediates, whose nature still constitutes a matter of debate. The first results seem to show that with the present high time resolution set-up, surface species can be detected under real operating conditions and a mechanistic approach will be discussed in a future self-standing paper.

\section{Conclusions}

A new IR operando reactor cell was built around a microwave cavity at $5.8 \mathrm{GHz}$. This new tool allowed efficient and timeresolved heating of the catalyst. The temperature of the catalyst under microwave irradiation can be measured by infrared emission time resolved spectroscopy. Desorption experiments with conventional and microwave heating illustrate the efficiency of the microwave heating in the reactor, allowing unsteady-state experiments. This new microwave reactor can be used to study surface reactions and reaction mechanisms by IR spectroscopy at high time resolution.

\section{Acknowledgements}

The authors wish to thank the company Covimag for technical support (and especially Mr. Ducrot), Région Basse Normandie for financial support, and Dr G. Whittaker for his help and fruitful discussions.

\section{References}

1 F. Thibault-Starzyk and J. Saussey, in In Situ Spectroscopy of Catalysts, ed. B. M. Weckhuysen, American Scientific Publishers, San Diego, 2004, p. 15.

2 J. Ryczkowski, Catal. Today, 2001, 68, 263.

3 R. Brosius, P. Bazin, F. Thibault-Starzyk and J. A. Martens, J. Catal., 2005, 234, 191.

4 T. Montanari, O. Marie, M. Daturi and G. Busca, Appl. Catal. B, 2007, 71, 216.

5 A. Wille and E. Fridell, Appl. Catal. B, 2007, 70, 294.

6 M. A. Bañares, Catal. Today, 2005, 100, 71.

7 B. M. Weckhuysen, Chem. Commun., 2002, 2, 97.

8 J. Pérez-Ramírez and E. V. Kondratenko, Catal. Today, 2007, 121, 160.
9 R. D. Cortright and J. A. Dumesic, Adv. Catal., 2001, 46, 161.

10 T. Engel and G. Ertl, Adv. Catal., 1979, $28,1$.

11 S. L. Shannon and J. G. Goodwin, Jr, Chem. Rev., 1995, 95, 677.

12 C. Bennett, Adv. Catal., 1999, 44, 329.

13 B. M. Weckhuysen, Phys. Chem. Chem. Phys., 2003, 5, 4351.

14 B. M. Weckhuysen, in In Situ Spectroscopy of Catalysts, ed. B. M. Weckhuysen, American Scientific Publishers, San Diego, 2004, p. 1

15 E. Groppo, C. Lamberti, S. Bordiga, G. Spoto and A. Zecchina, Chem. Rev., 2005, 105, 115.

16 T. Lesage, C. Verrier, P. Bazin, J. Saussey and M. Daturi, Phys. Chem. Chem. Phys., 2003, 5, 4435.

17 I. P. Silverwood, G. S. McDougall and A. G. Whittaker, Phys. Chem. Chem. Phys., 2006, 8, 5412.

18 I. Silverwood, G. McDougall and G. Whittaker, J. Mol. Catal. A, 2007, 269, 1

19 G. Bond and B. Moyes, in Microwave Enhanced Chemistry, ed. H. M. Kingston and S. J. Haswell, ACS Publications, Washington, 1997, p. 551.

20 X. Zhang and D. O. Hayward, Inorg. Chim. Acta, 2006, 359, 3421.

21 G. Bond, R. B. Moyes and D. A. Whan, Catal. Today, 1993, 17, 427.

22 D. Villemin and F. Caillot, Tetrahedron Lett., 2001, 42, 639.

23 X. Zhang, D. O. Hayward and D. M. P. Mingos, Chem. Commun., 1999, 11, 975.

24 X. Zhang, D. O. Hayward and D. M. P. Mingos, Catal. Lett., $2003, \mathbf{8 8}, 33$.

25 X. Zhang, D. O. Hayward, C. Lee and D. M. P. Mingos, Appl. Catal. B, 2001, 33, 137.

26 H. Will, P. Scholz and B. Ondruschka, Chem. Eng. Technol., 2004, 27, 2.

27 J. Ma, M. Fang, P. Li, B. Zhu, X. Lu and N. T. Lau, Appl. Catal. A: Gen., 1997, 159, 211.

28 A. de la Hoz, A. Diaz-Ortis and A. Moreno, Chem. Soc. Rev., 2005, 34, 164.

29 J. Beckers and G. Rothenberg, Chem. Phys. Chem., 2005, 6, 223.

30 D. A. C. Stuerga and P. J. Gaillard, J. Microwave Power Electromagn. Energy, 1996, 31, 87.

31 D. A. C. Stuerga and P. J. Gaillard, J. Microwave Power Electromagn. Energy, 1996, 31, 101.

32 H. An, C. Kilroy and P. J. McGinn, Thermochim. Acta, 2005, 435, 57.

33 M. Karches, H. Takashima and Y. Kanno, Ind. Eng. Chem. Res. Dev., 2004, 43, 8200.

34 S. F. Benjamin, R. J. Clarkson, N. Haimad and N. S. Girgis, SAE Paper, 1996, 961208.

35 L. Boltzmann, Ann. Phys. Chem., 1884, 22, 291.

36 D. Kajfez and A. Gundavajhala, Electron. Lett., 1993, 29, 1936. 